\title{
Modelling the Creep Curves of $\beta$-BOPP Film
}

\author{
Dong Zhiyuan, Fan Zepeng, Chen Yabo and Wang Kejian* \\ College of Mechanical and Electrical Engineering, Beijing University of Chemical Technology, China
}

Submission: March 18, 2021; Published: April 07, 2021

*Corresponding author: Wang Kejian, College of Mechanical and Electrical Engineering, Beijing University of Chemical Technology, China

Abstract

The effect of annealing on the creep and recovery properties of $\beta$-BOPP film was studied. The creep resistance can be improved obviously by annealing, the modification becomes better with elongating the duration. Four-parameter Burger model and Weibull distribution function well described such cases.

Keywords: BOPP Film; Creep; Fitting; Burger Model; Weibull Distribution Function

\section{Introduction}

Biaxially oriented polypropylene (BOPP) film has become a widely used film material because of its light weight, good transparency, moisture-proof, non-toxic and simple preparation process. When the content of $\beta$ crystal in BOPP is increased, the toughness and thermal deformation resistance of BOPP film is greatly improved such that its application scope is expanded. However, its internal structure will undergo such complex changes as the movement of chain segments, the unwinding of molecular chains and the change of free volume due to the long-term use [1], resulting in irrecoverable deformation causing failure. Therefore, it is of great significance to study the creep behavior of $\beta$-BOPP film for predicting its long-term reliability. As a simple and effective method to adjust polymer properties, annealing has been widely used in polymer processing. In the process, the relaxation is accelerated and the secondary crystallization may be promoted. In recent years, it is also an effective method to combine theoretical model and numerical simulation with experimental results. Drozdov [2] conducted the creep test of isotactic polypropylene under different stresses, the contributions of viscoelasticity and viscoplasticity are derived. Wang [3] found that the annealing process not only improved the crystallinity of $\beta$-PP samples, but also enhanced the mobility of amorphous segments. This paper aims to verify the validity of annealing on creep resistance of $\beta$ BOPP film.

\section{Experimental}

\section{Materials}

aPP (trade name E02ES) with a melt flow rate of $1.5 \mathrm{~g} / 10 \mathrm{~min}$ $\left(230{ }^{\circ} \mathrm{C} / 2.16 \mathrm{~kg}\right)$ and a density of $0.9 \mathrm{~kg} / \mathrm{m}^{3}$ was obtained from
Sinopec Zhenhai Refining and Chemical Co., Ltd. The $\beta$-nucleating agent (trade name ST-C, powder) was provided by Nanjing Chengkuan Trading Co.

\section{Sample preparations}

Firstly, PP pellets and nucleating agent were put in vacuum oven for drying at $70^{\circ} \mathrm{C}$ for $60 \mathrm{~min}$ to remove the residual moisture. After that, the nucleating agent was mixed into polypropylene in a high-speed mixer in weight percentage of $0.01 \%$ and $0.1 \%$. The mixture was extrudated and granulated as $\beta$-PP granule in a single screw extruder, after which $\beta$-BOPP film was obtained by blow molding. They are termed as $0.01 \mathrm{wt} \% \beta$-BOPP and $0.1 \mathrm{wt} \%$ $\beta$-BOPP respectively. The samples of $\beta$-BOPP film were annealed at $80{ }^{\circ} \mathrm{C}$ for $5 \mathrm{~min}, 15 \mathrm{~min}$ or $30 \mathrm{~min}$ respectively. They were then cooled to room temperature in air.

\section{Creep test}

DMA Q800 of TA company is used to test the creep properties of the film samples. The length $\times$ width of $20 \mathrm{~mm} \times 8 \mathrm{~mm}$ of the film is clamped on the tensile fixture in spacing of $10 \mathrm{~mm}$. The set invariants was the preload of $0.001 \mathrm{~N}$ at $80^{\circ} \mathrm{C}$ for the duration of $3 \mathrm{~min}$. The creep and recovery curves were obtained in test under the applied stress of $3 \mathrm{MPa}$ in the creep time of $15 \mathrm{~min}$ and the subsequent recovery time of $15 \mathrm{~min}$. The un-annealed samples refers to UA, ' $80-5^{\prime}$ refers to being annealed at $80^{\circ} \mathrm{C}$ for $5 \mathrm{~min}$.

\section{Results and Discussion}

\section{Experimental Results}

Figure 1 presents the creep-recovery curves of $0.01 \mathrm{wt} \% \beta$ BOPP (a) and $0.1 w t \% \beta$-BOPP (b) annealed in different durations 
at $80^{\circ} \mathrm{C}$. The first half of the curve is creep stage without creep fracture under the relatively small applied stress in short creep time. Upon unloading, the specimens can only recover to irrecoverable strain instead of zero strain irrespectively of a sudden drop in strain representing a quick part of elastic recovery followed by a gradual and slow recovery. The un-annealed $0.01 w t \% \beta$-BOPP in Figure 1a creeps to a higher content than the un-annealed $0.1 w t \% \beta$-BOPP in Figure $1 \mathrm{~b}$ due to higher $\beta$ crystallinity in the latter than the former. After annealing, the maximum creep strain and the final irrecoverable strain decrease obviously. Under the same stress, the dimensional stability of the film increases and the recovery property increases, indicating that the better creep resistance due to the static viscoelasticity. The higher the content of $\beta$ - crystal, the weaker the effects of annealing on creep resistance and elastic recovery. For the films with $0.01 \% \beta$ crystal content, the maximum strain decreases by $13.7 \%, 34.8 \%$ and $52.9 \%$, and the irrecoverable strain decreases by $41.1 \%, 47.7 \%$ and $65.9 \%$, respectively for annealing in durations of 5,15 and 30min. In camparison, for the films with $0.1 \% \beta$ crystal content, the maximum strain decreases by $9.6 \%$, $14.5 \%$ and $23.5 \%$, respectively, and the irrecoverable strain decreases by $12.8 \%, 15.6 \%$ and $34.4 \%$, respectively.

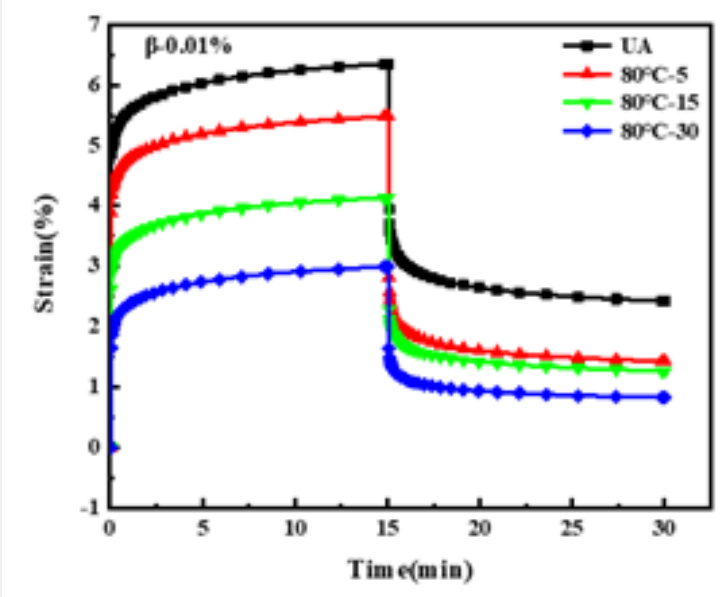

(a)

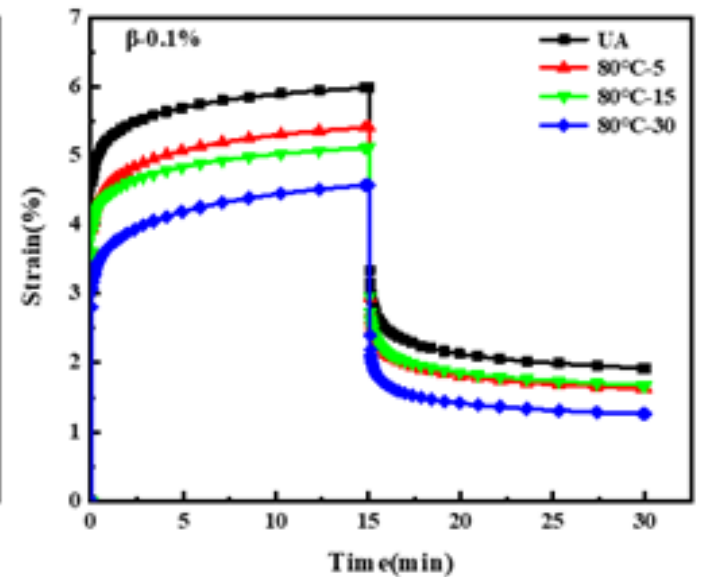

(b)

Figure 1: Creep-recovery of $0.01 w t \%(a)$ and $0.1 w t \% \beta$-BOPP (b) annealed in different durations at $80^{\circ} \mathrm{C}$.

\section{Modelling the creep and recovery}

\section{Burger model}

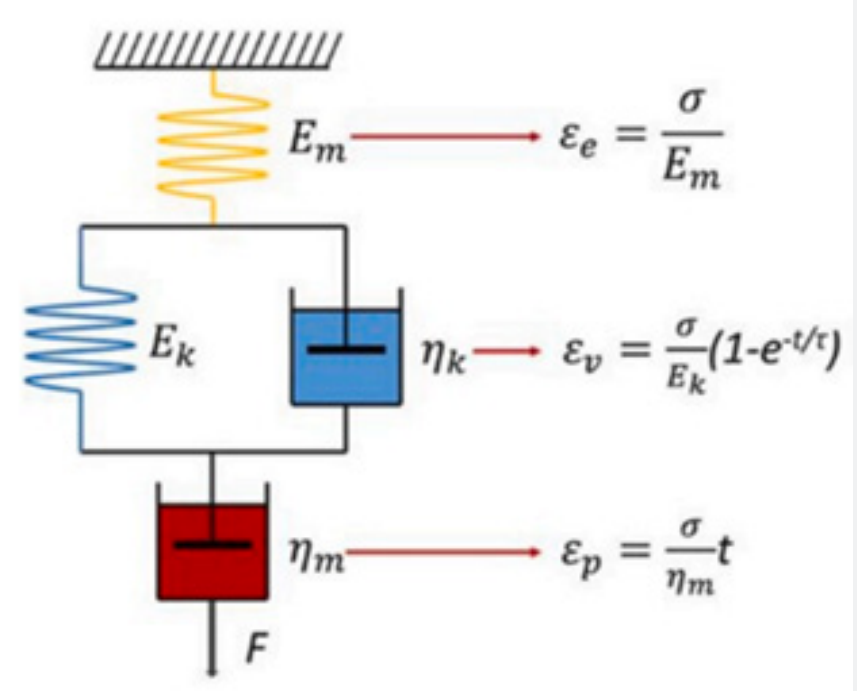

Figure 2: Schematic diagram of Burger model [4]. 
The Burger model, also known as four parameter model, is composed of Maxwell element and Kelvin Voigt element in series as shown in Figure 2, which is often used to analyze the creeprecovery. For linear viscoelastic solids, creep usually consists of three parts: instantaneous elastic deformation, delayed elastic deformation and flow deformation. The function of total strain with time under specific stress can be expressed by the following Eq.1.

$$
\begin{gathered}
\varepsilon_{c r}(t)=\varepsilon_{e}+\varepsilon_{v}+\varepsilon_{p} \\
\varepsilon_{c r}(t)=\frac{\sigma}{E_{m}}+\frac{\sigma}{E_{k}}\left(1-e^{-\frac{t}{\tau}}\right)+\frac{\sigma}{\eta_{m}} t, \tau=\frac{\eta_{k}}{E_{k}}
\end{gathered}
$$

where $\mathrm{t}$ is the loading time, $E_{m}$ is the modulus of the spring while $\eta_{m}$ is the viscosity of the adhesive pot in Maxwell model. $E_{k}$ is the modulus of the spring while $\eta_{k}$ is the viscosity in Kelvin model. $\tau=\eta_{k} / E_{k}$ is the delay time for deformation of $63.2 \%\left(1-\mathrm{e}^{4}\right)$ in Kelvin model. The values of those parameters $\left(E_{m}, \eta_{m}, E_{k}\right.$ and $\eta_{k}$ ) are calculated by nonlinear fitting of Eq.1 using Origin software. The coefficient $\mathrm{R}^{2}$ of fitting curve from experimental data is above 0.98, which indicates that the fitting effect is acceptable. The fitting curve is shown in Figure 3. The larger the value of in Maxwell model, the stronger the elasticity of the material. Once the stress is relieved, the strain produced in this part will disappear immediately. $E_{k}$ is used to characterize the rigidity of molecular chain in the material, which corresponds to the elastic modulus of spring element in Kelvin Voigt model. $\eta_{k}$ corresponds to the viscosity of the viscous pot assembly on the Kelvin Voigt model. The ratio of two represents relaxation time $\tau$. For specimens annealed in longer duration, $E_{m}, E_{k}$ and $\eta_{k}$ all become larger, indicating stronger elasticity and higher viscosity. $\eta_{m}$ is related to bulk viscosity of the material, which has a much higher effect on creep than $\eta_{k}$. The larger $\eta_{m}$, the smaller the irreversible deformation in the deformation process while the stronger the ability to restore the original size. The increase in $\eta_{m}$ means the strengthened friction resistance between molecules, being embodied by the decreased creep rate and the larger residual strain that cannot be recovered. Fitted values of parameters are also illustrated in Figure 4.The variations are very obvious.

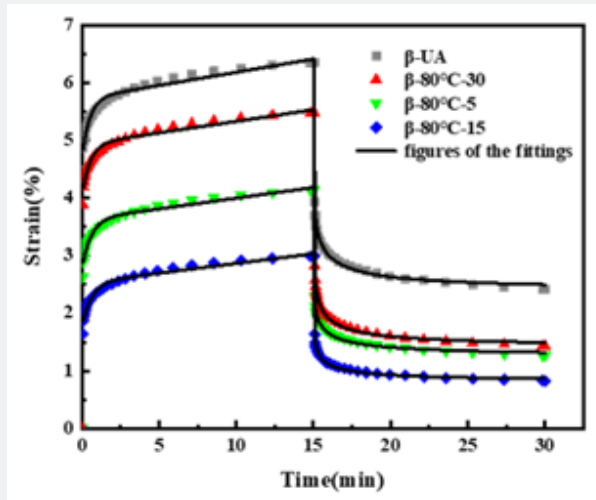

(a)

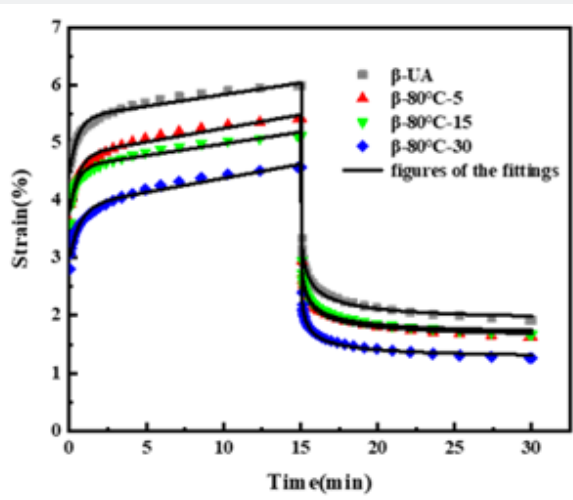

(b)

Figure 3: Creep-recovery stage fitting curves(a) $0.01 w t \% \beta$-BOPP (b) $0.1 w t \% \beta$-BOPP.
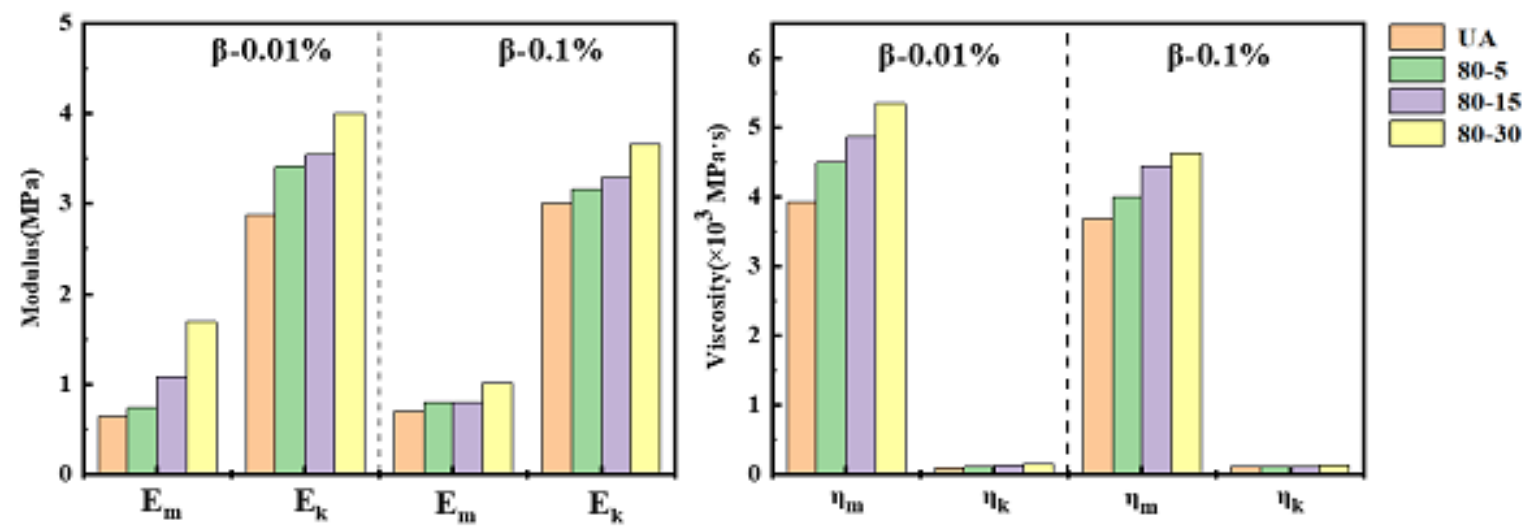

Figure 4: The fitted values of Burger model parameters for $\beta$-BOPP annealed in different durations. 


\section{Weibull distribution function}

Weibull distribution function is widely used to fit the strain recovery data of various polymers. When the load is removed, the elastic strain recovers instantaneously, and the subsequent strain is a time-dependent function as Eq.2.

$$
\varepsilon_{r e}(t)=\varepsilon_{v}\left[\exp \left(-\left(\frac{t-t_{0}}{\eta_{r}}\right)^{\beta_{r}}\right)\right]+\varepsilon_{p}
$$

In the formula of Eq.2, is the stress relief time. ${ }_{v}$ represents the delayed recovery strain, which is a function of time and is determined by the shape parameter $\beta_{r}$ and the characteristic life $\eta_{r} . \varepsilon_{v}$ is the permanent strain resulted by the viscous flow, which is the maximum permanent strain corresponding to the longest time in the creep test. The Weibull distribution function is used to fit the experimental data of recovery stage at $80^{\circ} \mathrm{C}$. The coefficient of determination $\mathrm{R}^{2}$ is above 0.99 , which shows that the fitting effect is reliable. The fitting curve is shown in Figure 3. The values of the parameters such as $\eta_{r}, \beta_{r}, \varepsilon_{v}$ and $\varepsilon_{p}$ are shown in Figure 5. The delayed recovery strain ( $\varepsilon_{v}$ ) first increases and then decreases after annealing while the unrecoverable strain $\left(\varepsilon_{p}\right.$ ) obviously decreases after annealing. The dimensional stability of the films under external force is enhanced.

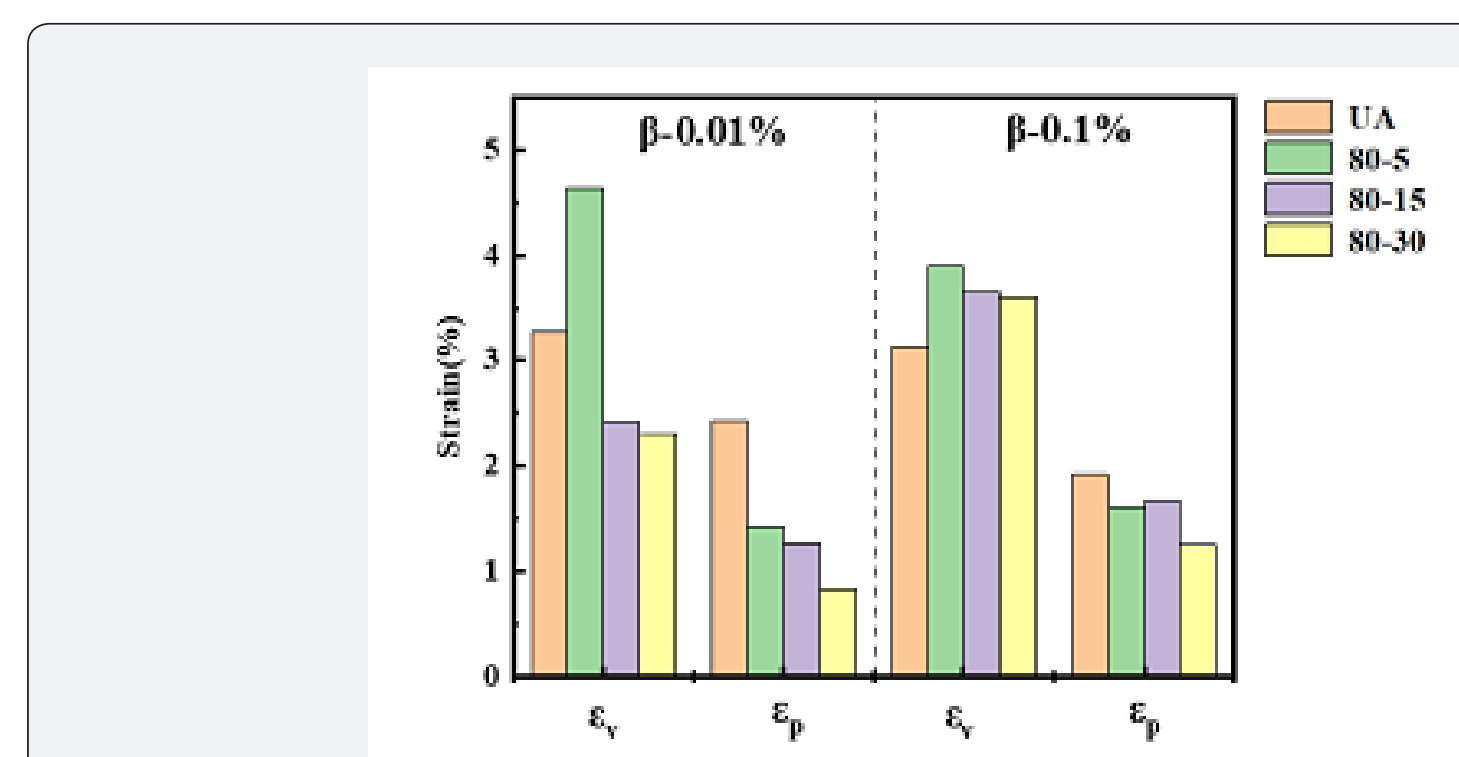

Figure 5: The fitted values of $\varepsilon_{v}$ and $\varepsilon_{p}$ for $\beta$-BOPP.

\section{Conclusion}

The creep and recovery of $\beta$ - BOPP films annealed for different durations are provided to be numerically described.

i. The resistance to creep and the size stability in recovery are improved by annealing at $80^{\circ} \mathrm{C}$. More $\beta$-crystallinity is also favorable for such modification of film.

ii. The Burger model and Weibull distribution function are well used to fit the experimental results. It is found that annealing can improve the elastic modulus, the bulk viscosity and the recovery ability of the film while reducing the creep rate and the irreversible deformation.

\section{References}

1. Yeo SS, Hsuan YG (2010) Evaluation of creep behavior of high density polyethylene and polyethylene-terephthalate geogrids. Geotextiles \& Geomembranes 28(5): 409-421.

2. Drozdov AD (2010) Creep rupture and viscoelastoplasticity of polypropylene. Eng Fracture Mechanics 77(12): 2277-2293.

3. Wang XW, Dai J, Chen JW, Jin D, Yang JH, Zhang JH, et al. (2015) Abnormal tensile creep behavior of annealed $\beta$-nucleated isotactic polypropylene. Industrial \& Eng. Chemistry Research 54(18): 49764987.

4. Xue C, Gao H, Hu Y, Hu G (2020)Experimental test and curve fitting of creep recovery characteristics of modified graphene oxide natural rubber and its relationship with temperature. Polymer Testing 87: 106509. 
(C) This work is licensed under Creative BY DOI: 10.19080/AJOP.2021.05.555651

\section{Your next submission with Juniper Publishers will reach you the below assets}

- Quality Editorial service

- Swift Peer Review

- Reprints availability

- E-prints Service

- Manuscript Podcast for convenient understanding

- Global attainment for your research

- Manuscript accessibility in different formats

( Pdf, E-pub, Full Text, Audio)

- Unceasing customer service

Track the below URL for one-step submission https://juniperpublishers.com/online-submission.php 